\title{
Compreensão de Termos Científicos no Discurso da Ciência
}

(Understanding scientific words in science discourse)

\author{
Maria Salete S. C. Pinheiro Leite e Maria José B. Marques de Almeida \\ Departamento de Física da Faculdade de Ciências e Tecnologia \\ Universidade de Coimbra, 3004-516, Coimbra, Portugal
}

Recebido em 18 de Maio de 2001. Aceito em 09 de Outubro de 2001.

\begin{abstract}
Neste trabalho são feitas considerações sobre a importância da compreensão da linguagem científica e da metalinguagem envolvida no discurso científico de professores e alunos e são relatados os resultados de dois estudos efectuados com o fim de detectar o grau de compreensão dos estudantes do Ensino Secundário e do Ensino Universitário de termos vulgarmente usados nas aulas e nos textos de Física. Com base nos resultados destes estudos fazem-se algumas sugestões para uma melhoria da qualidade do ensino de modo a obter-se uma aprendizagem mais significativa.
\end{abstract}

This paper deals with the importance of understanding the scientific terminology and the metalanguage used in the discourse of teachers and students in science classes. It relates the results of two studies directed to investigate the degree of understanding by high school and university students of the meaning of words commonly used in classes and text books of Physics. The results of this research allow the presentation of some suggestions to improve the quality of the teaching and learning processes.

\section{Introdução}

Sendo o ensino/aprendizagem um processo eminentemente socio-cultural (Vygotsky, 1986, 1987, Howe, 1996), é óbvia a importância da linguagem tanto escrita como oral para a aprendizagem das ciências.

$\mathrm{Na}$ evolução geral de um indivíduo, à medida que a linguagem e o pensamento se desenvolvem as componentes semânticas das palavras alteram-se e associam-se novos significados a palavras já conhecidas. Podemos entender como um processo semelhante a aquisição, na escola, de novos significados para certas palavras de uso comum, mas integrando agora uma linguagem que se quer cientificamente correcta.

A importância da linguagem e da sua prática no domínio das ciências da educação tem vindo a ser cada vez mais reconhecida. A oportunidade de se exprimir escrita e oralmente, explicando, prevendo e integrando novas informações em esquemas pré-existentes é um complemento essencial da aprendizagem, para o qual é fundamental utilizar uma linguagem correcta (Fellows, 1994, Rivard e Straw, 2000). Keys (1994) refere que mesmo os relatórios de trabalhos de laboratório, por vezes escritos em grupo, devem evidenciar as capaci- dades de raciocínio científico através da interligação de conceitos - o que apenas pode ser feito usandose a linguagem. Só praticando a utilização da linguagem através do processamento intelectual do que se lê ou se ouve nas aulas, num esforço de interligação de novos conceitos com ideias anteriores para preparar a aplicação a situações novas, e de um esforço no sentido de "dizer" ou "escrever" aquilo que se entende, é que se aprende (Muñoz-Chápuli, 1995, Etkina, 2000). Para Rivard (1994) escrever, não apenas para reproduzir exactamente o que se ouve ou lê, mas para gerar uma resposta pessoal a qualquer questão, para clarificar idéias, para construir e criar fundamentos para uma estrutura de conhecimento, é uma necessidade de que os alunos se devem aperceber. Mais uma vez é a linguagem, que tem de ser correcta nas suas vertentes de vocabulário, lógica e estrutural, que medeia todo este processamento (Keys, 1999, Whitworth, 1981, Maskill, 1988, Brincones e Otero, 1994, De Longhi, 2000). A linguagem é um elemento essencial no desenvolvimento dos processos de metacognição, entendida como o conhecimento, consciência e controlo pelos estudantes dos seus processos de aprendizagem (Thomas e McRobbie, 2001). 
Muitos autores (Meyerson et al. (1991), Kock e Eckstein (1991) e Norris e Phillips (1994)) têm referido a importância do conhecimento do discurso, tanto como do conhecimento do assunto científico, salientando a grande dificuldade que os alunos têm em entender a metalinguagem da ciência, isto é, a linguagem que exprime a textura e estrutura do conhecimento científico e permite falar sobre ciência e interpretar a sua estrutura argumentativa. Palavras tais como lei, teoria, observação, hipótese, método, conclusão, justificação, evidência, etc., integram a metalinguagem da ciência. Ter conhecimento desta linguagem para falar de ciência é tão importante como ter conhecimento dos próprios conceitos científicos, porque ela constitui um suporte necessário para uma interpretação crítica dos textos de ciências.

As limitações no entendimento da metalinguagem da ciência dificultam a interpretação dos textos que os alunos lêem ou das aulas a que assistem (Jacobs, 1989, Jonhstone e Su, 1994), e reduzem as capacidades de aprendizagem. Também a resolução de problemas é por vezes dificultada pelo mau conhecimento da metalinguagem científica (Rigden, 1987).

O desenvolvimento de um ensino construtivista, defendendo que ao aluno cabe a iniciativa de definir o conteúdo específico e o ritmo da aula, não se coaduna muito com os livros de texto tradicionais (Driver et al., 1994), necessariamente pré-estruturados para a transmissão de determinado conteúdo em determinada sequência. Além disso, a falta de critérios de selecção adequados para os livros de texto destinados ao ensino das ciências provocou um certo decaimento na ênfase dada à necessidade da leitura de livros de texto como actividade fundamental no processo de aprendizagem (Good, 1993, Holliday et al., 1994, Almeida e Mozena, 2000). Apesar de todas as potencialidades de ensino dos bons livros de texto (Glynn e Muth, 1994), os alunos não são ensinados a utilizá-los e na maioria dos casos não conseguem deles tirar o devido partido (Wandersee, 1988, Alexander e Kulikowich, 1994).

$\mathrm{O}$ tipo de linguagem utilizado pode permitir também, em situações favoráveis, criar padrões de identidade professor/aluno/disciplina eventualmente benéficos para atingir os fins propostos (Moje, 1995). Pode, no entanto, pelo contrário, contribuir para criar ou aumentar as dificuldades conceptuais dos alunos (Veiga et al., 1989). Assim, para além de praticar um tipo de ensino que deve ser adequado aos alunos que tem (Glasson e Lalik, 1993), deve o professor preocupar-se com perceber se as palavras que diz e as frases que constrói, e às quais atribui determinados significados, estão na realidade a ser entendidas pelos alunos com os mesmos significados (Klaassen e
Lijnse, 1996).

\section{Objectivos}

É incontroverso que a interpretação de um dado discurso escrito ou oral só pode ser correcta tendo em consideração o contexto em que as expressões são usadas, o que é tanto mais importante quanto é certo que os mesmos vocábulos podem ser usados em diversos contextos com significados diferentes. Muitas palavras do vocabulário corrente são usadas em Física com um significado preciso e bem definido, e frequentemente os alunos, familiarizados com o sentido comum dessas palavras, não se apercebem do seu significado específico no contexto da Física. Por outro lado os professores de Física do Ensino Superior têm como um dado adquirido o sentido específico desses termos e usam-nos naturalmente, sem se preocuparem em defini-lo ou clarificá-lo no contexto da disciplina.

O resultado é muitas vezes os estudantes pensarem que entenderam o que de facto não entenderam ou construírem, com base nos seus conhecimentos prévios e no sentido que atribuem às palavras, teorias incorrectas, não científicas, ou apreensões incorrectas de conceitos físicos. Grandezas definidas em ciência de um determinado modo podem, por isso, ser mal interpretadas no sentido de significarem qualquer coisa diferente.

O objectivo do presente trabalho foi o de verificar em que medida alunos do $12^{0}$ ano e dos primeiros anos do ensino superior, em áreas de ciências ou engenharia, possuem aquelas capacidades, isto é, são capazes de identificar e interpretar correctamente vocábulos em contexto científico, qual o seu domínio da metalinguagem da Física e qual a percepção que têm do seu próprio grau de entendimento.

\section{Método}

Foram feitos dois estudos paralelos: o primeiro - estudo A - envolveu alunos do $12^{0}$ ano (último ano do Ensino Secundário em Portugal) frequentando a disciplina de Física e alunos do $1^{0}$ ano frequentando a disciplina de Física Geral na Universidade de Coimbra, e tinha por objectivo investigar o seu grau de entendimento relativamente a um conjunto de 25 vocábulos integrando quer a linguagem comum quer a linguagem da Física, onde têm um significado específico (Tabela 1). A amostragem foi constituída, para o estudo A, por dois grupos, um dos quais de 141 alunos de Física Geral ( $1^{0}$ ano da Universidade) das licenciaturas em Física, em Engenharia e em Química, e outro de 130 alunos 
frequentando o $12^{0}$ ano do Ensino Secundário em cinco Escolas da Região de Coimbra.

O segundo - estudo B - envolveu alunos dos $2^{0}$ e $3^{0}$ anos das licenciaturas em Física e Engenharia Física na Universidade de Coimbra e tinha idênticos objectivos relativamente a um conjunto de 24 vocábulos que integram a metalinguagem da Física e que são frequentemente utilizados nas disciplinas de Física, onde constituem terminologia especializada (Tabela 2). Para o estudo B a amostragem foi constituída por 70 alunos.

Neste trabalho seguiu-se a metodologia utilizada por Jacobs (1989), tendo-se ainda, no conjunto dos dois estudos paralelos A e B, incluído a maior parte dos vocábulos e frases considerados por este autor. Não esquecendo que há especificidades nas duas línguas em causa, nomeadamente o português e o inglês, pretendeu-se aprofundar e alargar o âmbito do trabalho de Jacobs distinguindo entre vocábulos que são comuns na linguagem quotidiana portuguesa e com os quais os alunos tiveram o primeiro contacto num contexto não científico (estudo A) e vocábulos que, constituindo um suporte linguístico básico da própria Física, i.e., integrando a metalinguagem desta disciplina, são menos comuns no quotidiano, de modo que, com elevada probabilidade, o primeiro contacto dos estudantes com eles ocorreu num contexto científico.

Jacobs não distingue no seu estudo os vocábulos dos dois tipos. Por outro lado, a amostragem de Jacobs é idêntica a um dos grupos do nosso estudo A (o dos alunos do Ensino Superior). No presente trabalho, realizado com alunos portugueses, para além da confirmação ou não das observações de Jacobs na África do Sul, pretendeu-se verificar se, e em que medida, a frequência de uma disciplina de Física Geral no $1^{\mathrm{O}}$ ano do Ensino Superior alterava a situação relativamente ao ano imediatamente anterior (o último do Ensino Secundário).

$\mathrm{O}$ estudo $\mathrm{B}$, realizado com alunos do $2^{\mathrm{O}}$ e $3^{\mathrm{O}}$ anos da Universidade, que haviam frequentado já um número significativo de disciplinas especializadas de Física, deveria proporcionar, quer pela natureza da amostragem quer pelo carácter mais específico dos vocábulos usados, informação complementar à do estudo $\mathrm{A}$.

Assim, para cada um dos dois conjuntos de vocábulos em estudo foram elaborados dois testes: o primeiro, 1, continha um conjunto de frases, em cada uma das quais aparecia assinalada a negrito uma palavra. Havia uma frase para cada uma das palavras em estudo. Aos alunos era pedido que lessem cada frase e a classificassem com um símbolo de acordo com a seguinte convenção: se compreendiam o significado da palavra assinalavam a frase com $S$ (Sim), se não compreendiam assinalavam com $N$ (Não) e se tivessem uma ideia do significado da palavra mas não estivessem seguros assinalavam com $T$ (Tenho Dúvidas).

O objectivo deste teste era verificar qual a percepção que os alunos tinham do seu próprio entendimento relativamente ao significado dessas palavras no contexto daquelas frases. Ao responderem a este primeiro teste, os alunos ignoravam que teriam de responder a um segundo.

O segundo teste, 2, cujo objectivo era verificar o grau de correcção da percepção que os alunos tinham do seu próprio entendimento, continha o mesmo conjunto de frases do teste anterior, só que agora, a seguir a cada frase, eram propostos cinco possíveis significados ou opções para a palavra assinalada a negrito. Aos alunos era pedido que classificassem, no contexto da frase, cada uma dessas cinco opções em falsa $(\mathrm{F})$, verdadeira (V) ou não sei (NS).

Pedia-se que classificassem todas as alternativas, alertando-os para o facto de poder haver várias alternativas verdadeiras, bem como o de poderem ser todas falsas ou todas verdadeiras.

Os testes foram efectuados no decorrer de uma aula, todos no mesmo dia e hora nas diversas escolas ou turmas para que não houvesse condicionamentos nas respostas ao primeiro teste decorrentes do facto de os alunos conhecerem a existência e objectivos do segundo. Este requisito impediu também que o teste utilizado no estudo A fosse efectuado pelos alunos da amostra do estudo B, o que teria sido interessante; mas, não sendo exequível a realização de ambos os estudos (49 vocábulos) numa aula, optou-se pela solução descrita.

Os alunos foram informados de que os testes se integravam num estudo sobre problemas no ensino/aprendizagem da Física ligados à compreensão em contexto das palavras. Foi salientada a importância da sua colaboração e o seu carácter voluntário, traduzido pelo facto de não serem obrigados a responder ao inquérito. Todos responderam. Os exemplares dos questionários foram numerados, o que permitiu associar inequivocamente as respostas aos testes 1 e 2 de cada aluno, mantendo o seu anonimato. Para isso, o inquérito 1 foi recolhido simultaneamente com a entrega do inquérito 2, aluno a aluno, havendo o cuidado de verificar sempre que o número de ordem dos dois testes era o mesmo.

Todas as palavras, as frases em que se inserem e as opções propostas foram selecionadas com a preocupação de escolher vocábulos de uso muito frequente em diversos cursos de Física e de incluir, entre as opções propostas, significados correntes em discurso comum. 


\section{Resultados}

Os resultados destes estudos estão sintetizados nos gráficos 1,2 e 3 e na Tabela 3 .

A análise dos resultados foi feita de modo idêntico para os estudos A e B, tendo sido tratados separadamente os dados relativos aos dois grupos de estudantes que constituíram a amostragem do estudo A. Para cada uma destas populações determinou-se para cada questão $(\mathrm{Q})$ :

- A partir dos resultados do teste 1:

4.1 - A percentagem de respostas $\mathrm{S}$ (Sim), N (Não) e T (Tenho Dúvidas). Para cada população calcularam-se os valores médios destas variáveis, $\bar{S}, \bar{N}$ e $\bar{T}$.

- A partir dos resultados do teste 2:

4.2 - A percentagem de respostas certas, (5C), isto é, cujas cinco opções de significado foram classificadas correctamente em F (Falso) ou V (Verdadeiro). Para cada população calculou-se o respectivo valor médio, $(\overline{5 C})$.

4.3 - A percentagem de respostas, (4C), em que quatro das cinco opções de significado foram classificadas correctamente e a quinta incorrectamente ou em Não Sei (NS) e o respectivo valor médio $(\overline{4 C})$ para cada população.

4.4 - A percentagem I de respostas não correctas (ou seja, erradas mais NS) para cada opção de cada questão e o seu valor médio, $\bar{I}$, para todas as questões em cada estudo.

4.5 - A percentagem II de respostas "Não Sei" para cada opção de cada questão e o seu valor médio, $\overline{I I}$, para todas as questões em cada estudo.

4.6 - Para cada população foi calculado o valor médio $\bar{D}$ de um "índice de ilusão de saber" definido, para cada aluno, pela diferença entre a percentagem de respostas $\mathrm{S}$, (Sei), no teste 1 e a percentagem de respostas certas, $(5 \mathrm{C})$, no teste 2 .

4.7 - Também para cada população se calculou o valor médio $\bar{T}$ de um "coeficiente de insegurança" definido, para cada aluno, como a percentagem de respostas classificadas correctamente no teste $2,(5 \mathrm{C})$, mas relativas a palavras cujo significado indicavam no teste 1 não saber ou ter dúvidas (N ou T).

4.8 - O valor médio do grau de desconhecimento $\bar{G}$ definido como $\bar{G}=1-(\overline{5 C})$

\section{Discussão}

\subsection{Validade do instrumento de medida}

A própria natureza do método e a necessidade do factor "surpresa" associado ao segundo teste impediram a preparação e execução de um teste preliminar que permitisse detectar e corrigir eventuais defeitos na formulação das frases. No entanto, tendo tido o cuidado de consultar outros professores de Física do Departamento que se pronunciaram sobre o conteúdo e forma dos testes e utilizando a nossa própria experiência fundamentalmente baseada em provas de avaliação de alunos, crê-se ter conseguido salvaguardar bem a validade do instrumento de medida. Para detectar eventuais razões colaterais para as respostas dos alunos devidas a uma elaboração deficiente dos testes, embora não perceptível para Professores, foram seleccionadas todas as respostas com quatro opções correctas e apenas uma errada, tendo esta sido identificada. A análise, para estes casos, de qual a opção errada, mostrou que esta não se distribuiu de forma sistemática, a não ser quando estava claramente identificada com uma das conhecidas concepções alternativas dos alunos. Considera-se por isso que os resultados são válidos no âmbito da investigação proposta.

\subsection{Validade externa}

O facto de apenas cerca de $50 \%$ dos alunos da Faculdade de Ciências e Tecnologia da Universidade de Coimbra serem oriundos do próprio distrito permite generalizar ao País as conclusões obtidas com a amostra constituída pelos alunos universitários. Quanto à amostra constituída pelos alunos do $12^{0}$ ano, parece-nos que a generalização não pode ser estendida ao País, podendo no entanto ser generalizada ao distrito de Coimbra.

\subsection{Resultados do estudo A}

\subsection{1 - Análise estatística}

Nos gráficos 1 e 2 e na Tabela 3 apresentam-se, em percentagem, os valores dos parâmetros definidos no ponto 4 e calculados a partir das respostas dos alunos dos Ensinos Superior e Secundário, que permitem avaliar o seu conhecimento do sentido das palavras usadas e a percepção que têm desse conhecimento.

A percentagem de respostas $\mathrm{S}$ (teste 1) é elevada em quase todas as questões, o que se traduz em valores médios globais de $79 \%$ e $75 \%$ respectivamente, para alunos do Ensino Superior e Secundário, enquanto que é 
baixíssima a percentagem de respostas certas (teste 2), revelada pelos valores médios de $\overline{5 C}$ ( $8 \%$ e $7 \%$ respectivamente, para cada uma das populações referidas). Há pois um elevado grau de desconhecimento $(\bar{G}>90 \%)$ bem como uma elevada "ilusão de saber", traduzida por "graus de ilusão de saber" , $\bar{D}$, de $71 \%$ e $68 \%$ para os Ensino Superior e Secundário respectivamente.

A percentagem de respostas certas $(5 \mathrm{C})$ é sempre inferior a $30 \%$. Faz-se notar que em qualquer dos grupos há onze questões para as quais a percentagem de respostas certas é inferior a $5 \%$ e cinco para as quais se situa entre $5 \%$ e $10 \%$.

A percentagem de respostas $4 \mathrm{C}$, sendo como é natural esperar superior a $5 \mathrm{C}$, é também muito baixa, com valores médios de $21 \%$ e $19 \%$ para os alunos do Ensino Superior e do Ensino Secundário respectivamente.

Parece pois poder concluir-se que a maioria dos alunos não só não entende o significado das palavras em contexto, como não tem a percepção dessa falta de entendimento. A percentagem I de respostas que revelam a falta de conhecimento do significado específico do vocábulo é elevada (com valores $\bar{I}$ de $51 \%$ e $47 \%$ para os Ensinos Secundários e Superior, respectivamente) enquanto que a percentagem de respostas NS, indicando a consciência dessa falta de conhecimento, é relativamente baixa (com valores médios de $\overline{I I}$ de $16 \%$ e $12 \%$ para os Ensinos Secundário e Superior, respectivamente).

Por outro lado, e em contraste com o grau de "ilusão de saber", o coeficiente de insegurança é muito baixo $(\bar{T}$ $\leq 5 \%$ ), como se pode ver na Tabela 3 . Uma vez que este coeficiente é um indicador de medida das palavras cujo significado os alunos referiram no $1^{0}$ teste não saber, ou ter dúvidas, mas que classificaram correctamente no $2^{0}$ teste, isto é, cujo significado específico conheciam no contexto da física contra a sua própria expectativa, o seu baixo valor mostra que quando o aluno pensa que não sabe, o que acontece poucas vezes, em geral não sabe mesmo.

Contudo, a percentagem média global de respostas "Não sei" e/ou "Tenho dúvidas" (teste 1) é baixa (21\% e $25 \%$ para os alunos dos Ensinos Superior e Secundário, respectivamente) o que, associado à elevada percentagem de respostas "Sei" e ao elevado índice de ilusão de saber $(\bar{D})$ mostra que a consciência de "não saber" que o aluno acusa não encontra paralelo na consciência de "saber".

Assim, o aluno não sabe mas pensa que sabe, sendo muito reduzida a percepção da sua falta de conhecimento.

\subsection{2 - Análise de conteúdos}

A análise dos conteúdos dos inquéritos foi feita no sentido de identificar quais os vocábulos em que há erros mais frequentes e quais os conceitos que os alunos associam mais frequentemente a essas palavras, e de comparar o estudo dos dois grupos a fim de verificar a permanência ou erradicação desses erros após a frequência da disciplina de Física Geral. Referem-se, seguidamente, algumas conclusões deste estudo, consideradas com maior interesse.

Todas as palavras que integram este estudo, e que se indicam na Tabela 1, foram frequentemente utilizadas nas lições de Física Geral.

Analisando-se as opções dos alunos para os significados propostos para cada vocábulo no contexto da frase em que estava inserido, verificou-se que quer os alunos do $12^{0}$ ano, quer os do Ensino Superior, continuam a atribuir-lhes maioritariamente, o sentido comum.

A título de exemplo, podemos referir os mais frequentes (ocorrendo em percentagens próximas ou superiores a $50 \%)$ :

- identificação de "erro" com “inexactidão" , "possível engano", "incorrecção nas medidas", e a não associação a "precisão" ou "incerteza";

- identificação de "fraca precisão" com "pouca correcção", "pouco rigor" ou "pouco cuidado", e a não associação a "erro relativamente elevado";

- identificação de "aleatório" com "incerto", "caótico" e a não associação a "de acaso";

- identificação de "consumir energia" com "gastar energia", "desperdiçar energia" e a não associação a "transferir energia" ou "transformar energia";

- identificação de "constante universal" com "a mesma em todos os países do mundo", "valor convencional aceite por toda a comunidade científica" e a não associação a "a mesma para todas as substâncias";

- identificação de "interpretar" com "compreender" e a não associação a "construir uma teoria sobre";

- identificação de "justificar" com "provar matematicamente", "fazer a demonstração" ou "explicar o conteúdo";

- identificação de "parâmetro" com "incógnita" e a não associação a "factor ajustável"

- não identificação de "convenção" com "decisão consensual dos físicos"; 
- identificação de "evidência" com "indícios" e a não associação a "resultado de medições" ou "resultado de observações experimentais que não deixam lugar a dúvidas";

- identificação de "pouco provável" com "duvidoso";

- identificação de "lei" com "equação que liga dois fenómenos", "regra de comportamento" e a não associação a "equação entre grandezas"

- identificação de "ser função de" com "deduzir-se de", "só depender de" e a não associação a "varia com";

- identificação de "validade" com "precisão" ou com "alcance" e a não associação a "aplicabilidade"

- identificação de "aquecer" com "aumentar o calor"

Claro que isto tem repercussões não só ao nível da construção de conhecimentos, mas também ao nível elementar de interpretar uma pergunta, seja na aula, no estudo em casa ou numa prova de exame.

Como se mencionou em 5.3.1, a percentagem de respostas certas é inferior a $5 \%$ para algumas palavras, designadamente "observação", "fraca precisão", "aleatório", "parâmetro", "ciclos", "erro", "aquecer", "interpretar", "lei", "constante universal" e "evidência", situando-se entre $5 \%$ e $10 \%$ para "convenção", "sistema isolado", "estática", "radiação" e "justificar".

Os resultados são genericamente muito próximos para os dois grupos, podendo talvez considerar-se que o desempenho dos alunos do Ensino Superior tende a ser ligeiramente, mas apenas ligeiramente, melhor que o dos alunos do Ensino Secundário.

Tratando-se de vocabulário cujo domínio é essencial no contexto da física, é preocupante o elevado valor absoluto da ignorância inconsciente.

\subsection{3 - Comparação com os resultados de Jacobs}

Os resultados obtidos com a amostra do Ensino Superior podem comparar-se com os obtidos por Jacobs para o conjunto dos doze vocábulos comuns (frases números 1 a 10, 12 e 13 da Tabela 1), embora possam ter sido introduzidas algumas diferenças devidas ao desconhecimento das opções propostas por Jacobs como possíveis significados de muitas destas palavras.

Tendo em conta apenas os doze vocábulos, a percentagem de respostas $\bar{S}$ é de $76 \%$ para Jacobs e de $80 \%$ no presente trabalho, enquanto que a percentagem de respostas $\overline{5 C}$ é de $12 \%$ para Jacobs e de $8 \%$ neste estudo. Há, além disso, uma relação de valores idêntica para as respostas $\mathrm{S}$ e $5 \mathrm{C}$ para cada um daqueles vocábulos, com a curiosa excepção das palavras "intermitente" ( $\mathrm{S}=50 \%, 5 \mathrm{C}=4 \%$ em Jacobs, $\mathrm{S}=83 \%$, $5 \mathrm{C}=20 \%$ neste estudo) e "aleatório" ( $\mathrm{S}=84 \%, 5 \mathrm{C}=$ $28 \%$ em Jacobs, $\mathrm{S}=60 \%, 5 \mathrm{C}=4 \%$ neste trabalho), que reflectem provavelmente especificidades de cada língua.

Note-se ainda que as palavras "observação", "precisão" e "proporcional", destacadas por Jacobs por terem valores de $\mathrm{S}$ superiores a $80 \%$ e valores de $5 \mathrm{C}$ inferiores a $2 \%$, têm neste estudo valores de $\mathrm{S}$ superiores a $80 \%$ e valores de $5 \mathrm{C}$ de $2 \%, 1 \%$ e $11 \%$, respectivamente.

Assim, pode concluir-se que genericamente os resultados de ambos os trabalhos são concordantes mesmo quantitativamente, e que o problema é semelhante em dois países de língua e cultura tão diversa.

\subsection{Resultados do estudo B}

\subsection{1 - Análise estatística}

No gráfico 3 e na Tabela 3 apresentam-se também, em percentagem, os valores dos parâmetros definidos no ponto 4 , que permitem avaliar o conhecimento do sentido das palavras usadas neste estudo, bem como a percepção que os alunos têm desse conhecimento. Da análise destes resultados ressalta, mais uma vez, a elevada percentagem de respostas "Sei" relativamente aos conceitos apresentados no teste 1, comparada com a baixa percentagem de respostas certas (5C) no teste 2 .

Apesar de os vocábulos usados neste estudo integrarem a metalinguagem da Física e serem frequentemente utilizados em várias disciplinas que os alunos já frequentaram com sucesso, a análise da Tabela 3 mostra claramente uma elevada "ilusão de saber", $\bar{D}$, e a persistência de um elevado grau de desconhecimento, $\bar{G}$. O coeficiente de insegurança, $\bar{T}$, é relativamente elevado (13\%) para as circunstâncias curriculares destes alunos, salientando a fragilidade dos conhecimentos relativos a alguns conceitos expressos por vocábulos específicos.

\subsection{2 - Análise de conteúdos}

Esta análise foi feita nos mesmos moldes do estudo anterior. As palavras usadas neste estudo estão indicadas na Tabela 2 .

As respostas reflectem, tal como no estudo anterior, um grau elevado de desconhecimento do significado de muitos vocábulos comuns em disciplinas de Física Geral, em contexto físico. Referem-se a título de exemplo, alguns dos mais representativos (ocorrendo em percentagens próximas ou superiores a $50 \%$ ): 
- identificação de "denso" com "mais compacto", e a não associação a "com maior peso por unidade de volume";

- identificação de "ressonância" com "vibração", "ruído incómodo" ou "eco";

- identificação de "pressão" com "força" ou "compressão";

- identificação de "solução física" com "solução natural" ou "solução possível" e a não associação a "com significado físico";

- identificação de "frequência" com "ritmo";

- identificação de "partículas pontuais" com "corpos sem dimensões" e não com "corpos que não rodam em torno de si próprios";

- identificação de "origem sobre a trajectória" com "posição ocupada quando t $=0 "$

- identificação de "posição de equilíbrio" com "ponto mais baixo da trajectória" e não com "ponto em que a aceleração se anula";

- identificação de "níveis quantizados" com "há um número finito deles";

- identificação de "corrente alterna" com "varia periodicamente com o tempo" ou "sinusoidal" e não com "mudança periódica de sentido",

- identificação de "material radioactivo" com "combustível nuclear" ou "emissor de ondas de radiofrequência";

- identificação de "espectro de radiação" com "cores do arco-íris".

É evidente a persistência do significado comum das palavras que exprimem conceitos físicos bem definidos, assim como o desconhecimento do significado de vocábulos com os quais contactaram pela primeira vez em contexto científico e representam conceitos fundamentais em Física, correntemente usados em disciplinas já frequentadas.

\section{4 .3 - Comparação com os resultados de Jacobs}

Dada a diferença das amostras no estudo de Jacobs (alunos do $1^{\mathrm{O}}$ ano) e no presente trabalho (alunos dos $2^{\mathrm{O}}$ e $3^{\mathrm{O}}$ anos), os resultados obtidos para os seis vocábulos comuns a ambos os estudos não são directamente comparáveis.

Não deixa contudo de ser de notar, embora se não possam nem pretendam tirar conclusões, que para este conjunto de seis vocábulos, Jacobs obteve valores de $\bar{S}$ $=76 \%$ e $\overline{5 C}=28 \%$, sendo de $\bar{S}=82 \%$ e $\overline{5 C}=12 \%$ os obtidos no presente estudo.

\section{Conclusões e implicações para o ensino}

Relativamente aos objectivos do presente trabalho, foi possível concluir que é muito baixa, quer no ano terminal do Ensino Secundário quer no Ensino Superior, a capacidade de os alunos identificarem e interpretarem correctamente vocábulos em contexto científico, persistindo, mesmo após o ensino formal da Física, a atribuição do significado do discurso comum a vocábulos que integram esta linguagem.

O facto de os estudantes que tiveram ensino formal de Física Geral no Ensino Superior não terem desempenho significativamente melhor do que os alunos do $12^{0}$ ano deve ser motivo de reflexão, pois mostra que aqueles conceitos não foram apreendidos por uma percentagem significativa de alunos.

Por outro lado existe um elevado grau de desconhecimento da metalinguagem da Física, o que sem dúvida contribui para um acentuado insucesso escolar: não compreender o discurso científico oral ou escrito impede os alunos de entender os conceitos e até mesmo o conteúdo das questões apresentadas em testes de avaliação.

O desconhecimento desta linguagem específica é ainda agravado pela elevada ausência de percepção desse mesmo desconhecimento, pois a familiaridade das palavras ilude sobre o seu entendimento. Não se apercebendo de que não entende, o aluno não sente necessidade de se esforçar no sentido de tentar compreender o significado correcto das palavras que está a ouvir ou a ler.

Sendo a linguagem o veículo de comunicação entre o professor e o aluno, a atribuição de significados diferentes aos mesmos vocábulos pode levar o aluno a construir o seu próprio conhecimento de acordo com esquemas alternativos eventualmente incorrectos. A falta de percepção, pelo professor, desta situação de comunicação deficiente, alimenta no aluno aqueles esquemas, ou pode mesmo dar-lhes origem, levando ao desenvolvimento da "ciência do aluno", de erradicação muito difícil.

Aprender significa muito mais do que obter informação: significa processá-la, inseri-la na informação anterior, reconsiderar e eventualmente alterar esquemas de compreensão, ou seja, criar uma estrutura segura, embora simples, formada por conceitos e leis e na qual os fenómenos do dia a dia se possam enquadrar e interligar. 
É essencial que os educadores estejam atentos e conscientes dos conflitos conceptuais inerentes a certos vocábulos científicos e não assumam um conhecimento semântico apenas porque os alunos demonstram possuir conhecimento fonético.

Tem sido salientada por diversos investigadores a necessidade de levar o aluno a exprimir-se por palavras suas, quer sob a forma oral quer escrita, nomeadamente promovendo a discussão oral em grupo, de conteúdos (Meyer e Woodruff, 1997, Towns e Grant, 1997), a apresentação e discussão de relatórios escritos de trabalhos laboratoriais (Roth et al., 1997) ou de investigação científica (Keys, 1999), ou a resolução detalhada de problemas (Larkin et al., 1980, Austin, 1998). Também no Ensino Superior foi testado o fomento da expressão escrita dos alunos como meio de desenvolver a sua participação na própria aprendizagem (MuñozChápuli, 1995, de Almeida, 1999, Leite, 1999, Etkina, 2000): ao escrever sobre um determinado conceito ou fenómeno, o aluno evidencia o modo como o seu conhecimento está organizado, o que o leva a desenvolver o raciocínio e a interligação entre conceitos.

Os resultados do presente trabalho devem levar a uma profunda reflexão sobre os conteúdos e métodos do ensino, mesmo no Ensino Superior, nomeadamente na relação extensão/profundidade dos curricula, apontando fortemente para a indispensabilidade de criar mecanismos de "feed-back" que permitam que professor e aluno possam avaliar, durante o próprio processo de ensino/aprendizagem, o grau de sintonia entre os seus discursos.

Deve ser fomentada a necessidade de o aluno "dizer as coisas por palavras suas", "escrever resumos do que lê" ou "estudar em voz alta", pois pôr as coisas em palavras próprias centra a atenção, clarifica o raciocínio, fornece um meio de concretização do pensamento através de símbolos e é parte integrante do processo de formação de conceitos.

\section{References}

[1] Alexander, P.A. e Kulikowich, J.M. (1994). Learning from physics texts: a synthesis of recent research. Journal of Research in Science Teaching 31 (9), 895-911.

[2] Almeida, M.J.P.M. e Mozena, E.R. (2000). Luz e outras formas de radiação electromagnética: Leituras na $8^{a}$ série do Ensino Fundamental. Revista Brasileira de Ensino de Física, 22, 426-433.

[3] Austin, L. (1998). Choosing concepts for investigation. Physics Education, 33, 114-119.

[4] Brincones, I. e Otero, J. (1994). Students' conceptions of the top-level structure of physics texts. Science Education, 78, 171-183.
[5] de Almeida, M.J.M. (1999). Uma experiência de avaliação contínua na disciplina de Didáctica da Física. $9^{0}$ Encuentro Ibérico para la Enseñanza de la Física, Valência, Espanha.

[6] De Longhi, A.L. (2000). El discurso del professor y del aluno: análisis didactico en classes de ciências. Enseñanza de las Ciências, 18, 201-216.

[7] Driver, R., Asoko, J., Leach, J. Mortimer, E. e Scott, P. (1994). Constructing science knowledge in the classroom. Educational Research 23, 5-12.

[8] Etkina, E. (2000). Weekly reports: a two-way feedback tool. Science Education, 84, 594-605.

[9] Fellows, N.J. (1994). A window into thinking: using student writing to understand conceptual change in science learning. Journal of Research in Science Teaching, 31, 985-1001.

[10] Glasson, G.E. e Lalik, R.V. (1993). Reinterpreting the learning cycle from a social constructivist perspective: a qualitative study of teachers' beliefs and practices Journal of Research in Science Teaching, 30, 187- 207.

[11] Glynn, S.M. e Muth, K.D. (1994). Reading and writing to learn science: achieving scientific literacy. Journal of Research in Science Teaching 31 (9), 1057-1073.

[12] Good, R. (1993). Editorial: Science textbook analysis. Journal of Research in Science Teaching, 30, 619.

[13] Holliday, W.G., Yore, L.D. e Alvermann, D.E. (1994). The reading-science learning-writing connection: breakthroughs, barriers and promises. Journal of Research in Science Teaching, 31 (9), 877-893.

[14] Howe, A.C. (1996). Development of science concepts within a Vygotskian framework. Science Education, 80, 35-51.

[15] Jacobs, G. (1989). Word usage misconceptions among first-year university physics students. International Journal of Science Education, 11, 395-399.

[16] Johnstone, A.H. e Su, W.Y. (1994). Lectures - a learning experience? Education in Chemistry, 31, 75-79.

[17] Keys, C.W. (1994). The development of scientific reasoning skills in conjunction with colaborative writing assignments: an interpretative study of six ninth-grade students. Journal of Research in Science Teaching, 31, 1003-1022.

[18] Keys, C.W. (1999). Language as an indicator of meaning generation: an analysis of middle school students written discourse about scientific investigations. Journal of Research in Science Teaching, 36, 1044-1061.

[19] Klaassen, C.W.J.M. e Lijnse, P.L. (1996). Interpreting students' and teachers' discourse in science classes: an underestimated problem? Journal of Research in Science Teaching, 33, 115-134.

[20] Kock, A. e Eckstein, S.G. (1991). Improvement of reading comprehension of physics texts by students' question formulation. International Journal of Science Education, 13, 473-485.

[21] Larkin, J.H., McDermott, J., Simon, D.P. e Simon, H.A. (1980). Expert and novice performance in solving physics problems. Science, 208, 1335-1342. 
[22] Leite, M.S.P. (1999). Uma experiência de avaliação em Mecânica. $9^{0}$ Encuentro Ibérico para la Enseñaza de la Física, Valência, Espanha.

[23] Maskill, R. (1988). Logical language, natural strategies and the teaching of science. International Journal of Science Education, 10, 485-495.

[24] Meyer, K e Woodruff, E. (1997). Consensually driven explanation in science teaching. Science Education, 80, 173-192.

[25] Meyerson, M.J., Ford, M.S., Jones, W.P. e Ward, M.A. (1991). Science vocabulary knowledge of third and fifth grade students. Science Education, 75, 419-428.

[26] Moje, E.B. (1995). Talking about science: an interpretation of the effects of teacher talk in a high school science classroom. Journal of Research in Science Teaching, 32 (4), 349-371.

[27] Muñoz-Chápuli, R. (1995). Escribir para aprender: ensayo de una alternativa en la enseñanza universitaria de las ciencias. Enseñanza de las Ciencias, 13, 273-278.

[28] Norris, S.P. e Phillips, L.M. (1994). Interpreting pragmatic meaning when reading popular reports of science. Journal of Research in Science Teaching, 31, 947-967.

[29] Rigden, J.S. (1987). Editorial. Problem-solving skill: what does it mean? American Journal of Physics, 55, 877.

[30] Rivard, L.P. (1994). A review of writing to learn in science: implications for practice and research. Journal of Research in Science Teaching, 31, 969-983.

[31] Rivard, L.P. e Straw, S.B. (2000). The effect of talk and writing on learning science: an exploratory study. Science Education 84, 566-593.
[32] Roth, W.M., McRobbie, C.J., Lucas, K.B. e Boutonné, S. (1997). Why my students fail to learn from demonstrations? A social practice perspective on learning in physics. Journal of Research in Science Teaching, 34, 509-533.

[33] Thomas, G.P. e McRobbie, C.J. (2001). Using a metaphor for learning to improve students metacognition in the chemistry classroom. Journal of Research in Science Teaching, 38, 222-259.

[34] Towns, M.H. e Grant, E.R. (1997). "I believe I will go out of this class actually knowing something": cooperative learning activities in physical chemistry. Journal of Research in Science Teaching, 34, 819-835.

[35] Veiga, M.L.F.C.S., Costa Pereira, D.J.V. e Maskill, R. (1989). Teachers' language and pupils' ideas in science lessons: can teachers avoid reinforcing wrong ideas? International Journal of Science Education 11 (4), 465479.

[36] Vygotsky, L.S. (1986). Thought and language. (A. Kozulin, Trans.) Cambridge M.A.: MIT Press (original English translation published 1962).

[37] Vygotsky, L.S. (1987). Thinking and speech. In R.W. Rieber and A.S. Carton (Eds) "The collected works of L.S.Vygotsky. Vol I: Problems of general psychology" (N. Minick, Trans.) New York: Plenum Press (original work published 1934).

[38] Wandersee, J.H. (1988). Ways students read texts. Journal of Research in Science Teaching, 25 (1),69-84.

[39] Whitworth, R.W. (1981). The language of physics. Physics Education, 16, 65. 
Tabela 1 - Frases usadas no teste 1 do estudo A

1- Uma miragem é um fenómeno natural

2- O funcionamento do amplificador era intermitente devido a um mau contacto

3- As observações foram feitas independentemente umas das outras

4- A validade da lei de Hooke é questionável para grandes distensões

5- A área da esfera foi medida com fraca precisão

6- A potência de entrada para um oscilador é uma função da frequência

7- A radioactividade de um átomo é um fenómeno aleatório

8- O comprimento do pêndulo é um parâmetro na equação do período.

9- Muitos fenómenos em física podem associar-se a ciclos

10- Vamos estudar análise de erros

11- É muito pouco provável que dois electrões do mesmo átomo ocupem simultaneamente o mesmo elemento de volume

12- A grandeza do campo gravítico é proporcional à massa do corpo que o cria

13- Por convenção, considera-se positivo o sentido para a direita numa direcção horizontal

14- Conserva-se constante a energia de um sistema isolado

15- Liga-se um aquecedor eléctrico para aquecer uma sala no Inverno

16- Podemos interpretar os resultados das experiências de Galileu

17- A lei de Ohm é válida para certo tipo de condutores

18- Estamos a consumir muita energia

19- Se houver resistência do ar a queda de um corpo é um movimento amortecido

20- Ao fim de um certo tempo atingiu-se uma situação estática

21- O número de Avogadro é uma constante universal

22- É a radiação do Sol que ilumina a Terra

23- Há evidência do spin do electrão

24- Deve justificar-se qualquer resposta a uma questão sobre uma situação física

25- Existe uma relação entre a temperatura do ar e a hora do dia a que esta se mede 
Tabela 2 - Frases usadas no teste 1 do estudo B

1- O ferro é mais denso que o cobre.

2- Ocorre uma ressonância quando a frequência da força motora iguala a frequência natural do oscilador.

3- A pressão a que um corpo fica sujeito num líquido depende da profundidade a que se encontra.

4- A segunda raiz de uma equação do $2^{0}$ grau não correspondia a uma solução física.

5- A frequência de uma vibração depende da dureza da mola que vibra.

6- As leis de Newton, num sentido restrito, só se aplicam a partículas pontuais.

7- O corpo A não tem carga eléctrica.

8- O calor específico de um sólido tende para zero quando a temperatura tende para o zero absoluto.

9- A água do copo do João evaporou-se.

10- A posição de uma partícula sobre uma trajectória só fica bem caracterizada se for definida em relação a uma origem sobre essa trajectória.

11- Uma partícula, ao executar um movimento oscilatório passa várias vezes pela posição de equilíbrio.

12- $\mathrm{A}$ roda $\mathrm{A}$, maciça, tem maior inércia que a roda $\mathrm{B}$, raiada.

13- Sinto o tapete da casa de banho menos frio que o chão de azulejo.

14- O motor do meu automóvel tem muita potência.

15- A altura aparente das estrelas é maior do que a altura real.

16- A energia cinética de um corpo é uma função crescente da sua velocidade.

17- A força devida a um campo gravítico é uma força conservativa.

18- Os níveis energéticos de um átomo são quantizados.

19- O efeito fotoeléctrico confirmou o postulado de Planck.

20- Num acelerador de partículas, os electrões atingem velocidades relativistas.

21- Vamos estudar circuitos eléctricos em regime estacionário.

22- Nas nossas casas, a corrente eléctrica é alterna.

23- O plutónio é um material radioactivo.

24- O espectro da radiação electromagnética solar é continuo. 
Tabela 3 - Análise estatística das respostas aos estudos A e B

\begin{tabular}{|l|c|c|c|}
\cline { 2 - 3 } \multicolumn{1}{c|}{} & \multicolumn{2}{c|}{ Estudo A } & \multirow{2}{*}{ Estudo B } \\
\cline { 1 - 3 } Valores médios (em \%) & Ensino Superior & Ensino Secundário & \\
\hline Ilusão de saber $\bar{D}$ & $71 \%$ & $68 \%$ & $63 \%$ \\
\hline Coeficiente de insegurança $\bar{T}$ & $3 \%$ & $5 \%$ & $13 \%$ \\
\hline Respostas $(\bar{S})$ & $79 \%$ & $75 \%$ & $78 \%$ \\
\hline Respostas certas $(\overline{5 C})$ & $8 \%$ & $7 \%$ & $16 \%$ \\
\hline Grau de desconhecimento $\bar{G}$ & $92 \%$ & $93 \%$ & $84 \%$ \\
\hline Respostas (erradas + NS) $\bar{I}$ & $47 \%$ & $51 \%$ & $39 \%$ \\
\hline Respostas (NS) $\overline{I I}$ & $12 \%$ & $16 \%$ & $10 \%$ \\
\hline
\end{tabular}

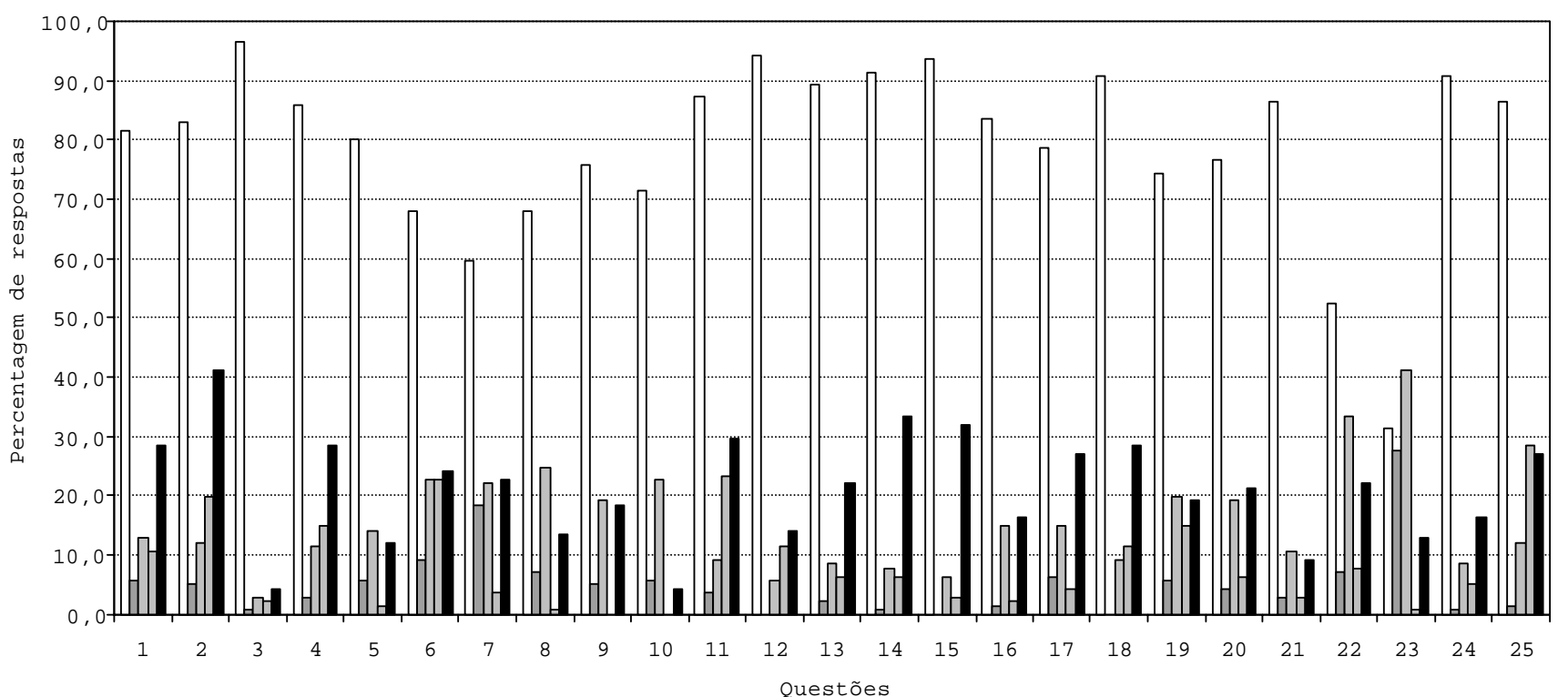


Gráfico 2 .

Estudo A - Ensino Secundário (130 alunos)

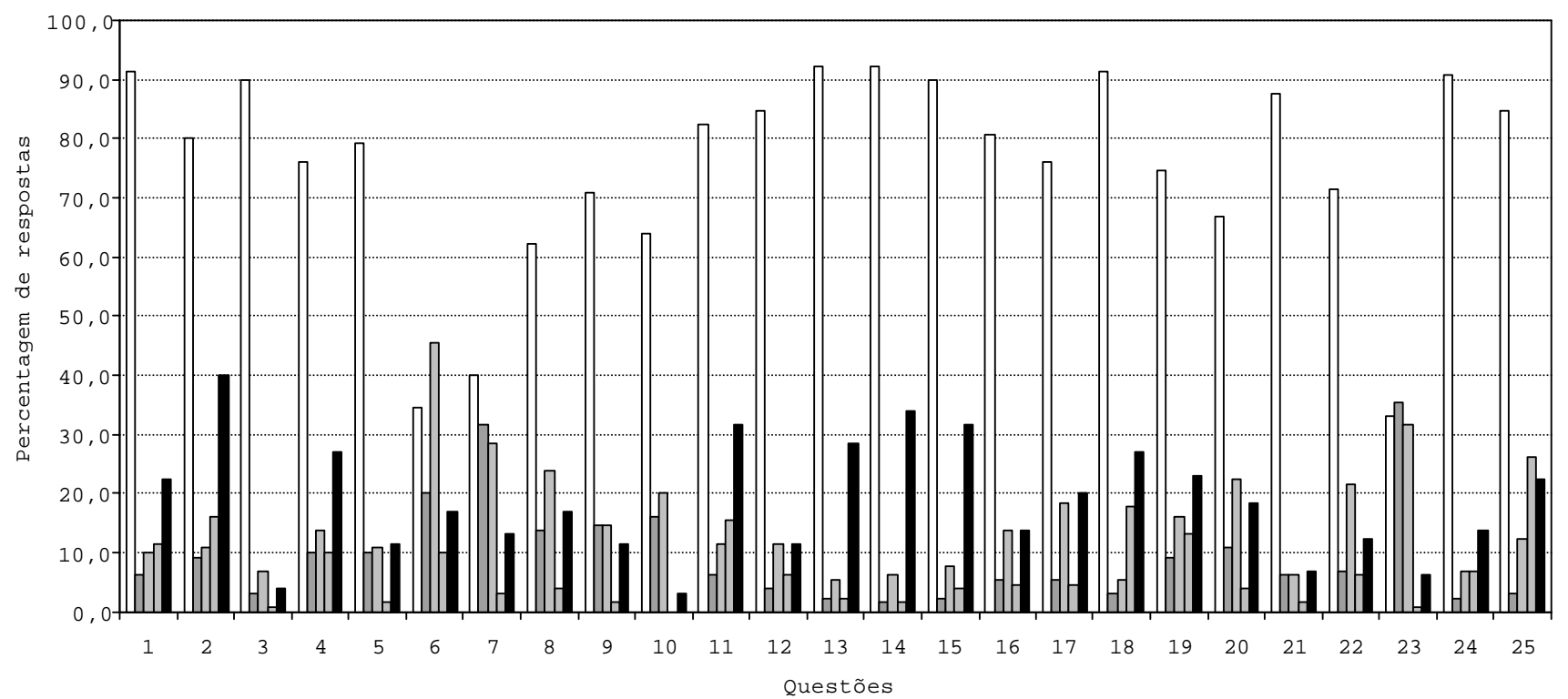

-4C. 4 opções classificadas correctamente e 1 incorrectamente

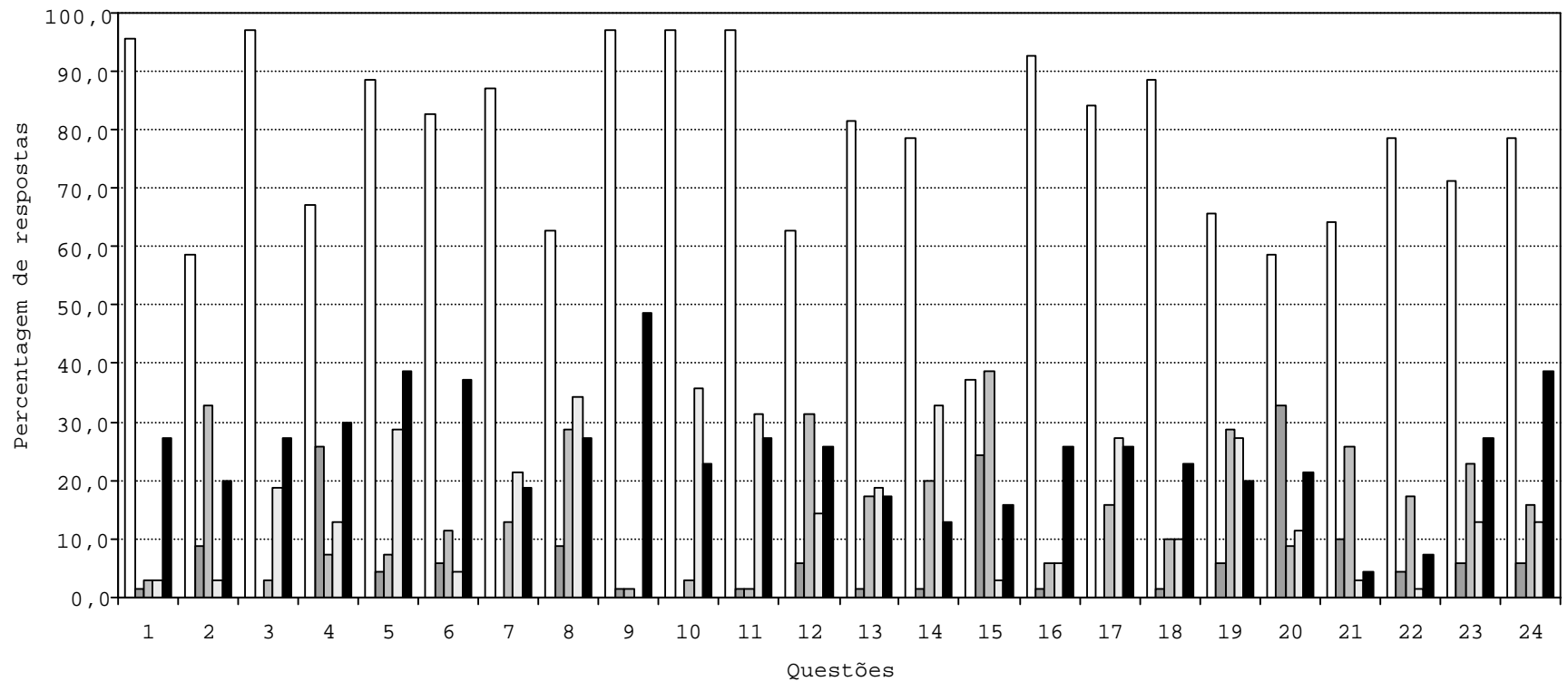

G. Sim

$\square$ T. Tenho dúvidas

$\square_{\mathrm{N}} \cdot \mathrm{Não}$

4C. 4 opções classificadas correctamente e 1 incorrectamente 